\title{
Connexins in the early development of the African clawed frog Xenopus laevis (Amphibia): The role of the connexin43 carboxyl terminal tail in the establishment of the dorso-ventral axis
}

\author{
Jaime Cofre ${ }^{1}$ and Eliana Abdelhay ${ }^{2}$ \\ ${ }^{1}$ Laboratório de Embriologia Molecular, Universidade Federal de Santa Catarina, Florianópolis, \\ SC, Brazil. \\ ${ }^{2}$ Laboratório de Biologia Molecular Maury Miranda, Instituto de Biofísica Carlos Chagas Filho, \\ Universidade Federal do Rio de Janeiro, Rio de Janeiro, RJ, Brazil.
}

\begin{abstract}
Connexins are a family of related proteins identified in vertebrate forming gap junctions, which mediate cell-to-cell communication in early embryos, with an important role in establishing embryonic asymmetry and "communication compartments'. By in situ hybridization, immunocytochemistry, reverse transcriptase PCR (RT-PCR) and western blotting we show that a Cx43-like molecule is present in oocytes and embryos of the African clawed frog Xenopus laevis, with specific localization in the animal-vegetal axis. This specific distribution is suggestive for an important role for this protein in the establishment of the dorso-ventral axis. Antisense RNA and antibodies directed against rat carboxyl terminal tail of the Cx43 (CT-Cx43) and injected in 1-cell stage Xenopus embryos, induced pronounced alterations in nervous system development, with a severe ventralization phenotype. Coherently, the overexpression of CT-Cx43 produced a dorsalization of the embryos. In antisense treated embryos, the expression of the $\beta$-catenin gene is eliminated from the Nieuwkoop center, the pattern expression of the Chordin, Xnot and Xbra is modified, with no effect in expression of the Goosecoid gene. In CT-Cx43 mRNA treated embryos the pattern of expression of the $\beta$-catenin, Chordin, Goosecoid, Xnot and engrailed-2 genes is modified. The expression of $\beta$-catenin is increased in the Nieuwkoop center, the expression pattern of Chordin and Goosecoid is expanded to the posterior neural plate and engrailed-2 presents ectopic expression in the ventral region. Taken together our data suggest a role for CT-Cx43 as a maternal determinant with a critical function in the formation of the dorso-ventral axis in Xenopus laevis. The Cx43 may be one of the earliest markers of the dorso-ventral axis in these embryos and could possibly be acting through regionalization of factors responsible for the establishment of this axis.
\end{abstract}

Key words: connexins, carboxyl terminal tail, dorso-ventral axis, early development in amphibians, Xenopus laevis

Received: December 14, 2005; Accepted: November 3, 2006.

\section{Introduction}

During the past several years, mouse genetic approaches (Lo, 1999) and dominant negative techniques in frogs of the genus Xenopus (Paul et al., 1995) have demonstrated that cell-cell communication via gap junction channels has an important role in establishing embryonic asymmetry during early development (Levin and Mercola, 1998; Levin and Mercola, 1999) and maintenance of appropriate organ function during adult life (Lo, 1996). The essential role of gap junctions for normal development in Xenopus was suggested by experiments in which disruption of gap junctional communication using an anti-

Send correspondence to Jaime Cofre. Laboratório de Embriologia Molecular, sala 313b, Campus Universitário S/N, Bairro Trindade, 88040-900 Florianópolis, SC, Brazil. E- mail: gcofre@ccb.ufsc.br. connexin antibody injected into a dorsal blastomere led to the loss of anterior-dorsal structures (Warner et al., 1984). Additionally, experiments using the microinjection of dominant negative and wild type connexin mRNAs clearly showed that dorso-ventral differences in gap junctional communication within the early embryo are needed in leftright patterning (Levin and Mercola, 1998; Levin and Mercola, 1999).

Six Xenopus connexins have been identified to date. The Cx30 which appears at the gastrula and tailbud stages (Gimlich et al., 1988, 1990), the Cx41 which is not detected until adulthood (Bruzzone et al., 1996) and four maternal connexins: Cx43, Cx43.4, Cx31 (Landesman et al., 2003) and Cx38 (Gimlich et al., 1988, 1990). Unlike Cx38, expression of $\mathrm{Cx} 31, \mathrm{Cx} 43$ and $\mathrm{Cx} 43.4$ continue zygotically (Landesman et al., 2003) 
The establishment of the dorso-ventral axis is a critical initial step in pattern formation but how polarity originates and is maintained is not well understood. Several studies have suggested that in Xenopus embryos the earliest step in dorsal axis formation involves the rotation of cortical cytoplasm in the fertilized egg, and this rotation is postulated to localize cytoplasmic dorsal determinants in the future dorsal side (Yuge et al., 1990). This process induces dorsal expression of regulatory genes, which in turn establish the Spemann organizer at the start of gastrulation (Kageura, 1997). The Wnt, Vg1 and Noggin factors have dorsal determining activity, but do not display polarized dorso-ventral expression or activity during early development in Xenopus. Thus, attention has turned to the cytoplasmic components of these pathways. The principal downstream signaling target of Wnt- 1 is a $\beta$-catenin (Larabell et al., 1997) and its overexpression is sufficient to induce a complete secondary axis (Guger and Gumbiner, 1995; Sokol et al., 1995).

Xenopus embryos exhibit a polarity in gap junctional permeability at the 32-cell stage, as dorsal blastomeres transfer the dye Lucifer Yellow more frequently than do ventral blastomeres (Guthrie, 1984). The gap junctional permeability is increased between ventral animal pole cells in Xenopus embryos treated with dorsalizing agents like lithium chloride (Nagajski et al., 1989), Wnt-1 and Wnt-8 (Olson et al., 1991). The dorso-ventral pattern and its relation to cell coupling was further reinforced by studies with ultraviolet light, in which a ventro-posterior phenotype was observed, with a concomitant decrease in dye transfer on the dorsal side of the embryo (Nagajski et al., 1989). Thus, ventralization seems to correlate with reduced dye transfer activity, while increased dye transfer correlates with dorsalization. These studies support the idea that gap junction channels may be involved in coordinating dorso-ventral polarity in the early embryo, although no direct experimental evidence has yet been presented in favor of such a model.

In recent years, some evidence for the participation of connexins hemi-channels in cellular physiology has appeared, contributing in diverse and different processes as apoptosis, cellular proliferation, tumor growth, calcium wave propagation and ephaptic neuronal communication (Goodenough and Paul, 2003). These evidence indicates that connexins have independent functions besides cell-cell communication and also in many cases these functions are independent of the cellular membrane. Segretain et al. (2003) showed that the proliferation of tumor lines is associated with intracellular sequestration of endosomal $\mathrm{Cx} 43$ and, therefore, not inserted in the cellular membrane. Moreover Zhang et al (2003) demonstrated that the injection of the Cx43 carboxyl tail alone is enough to produce a tumor suppressor effect. However, the role of cellular communication in this process was completely excluded by the experiments of Olbina and Eckhart (2003), in which a mutant of $\mathrm{Cx} 43$ for the second extracellular region was created. Immunofluorescence detected the mutant protein in the cytoplasm but not in the plasmatic membrane, however, the effect of cellular growth suppression still was observed. At present, it cannot be affirmed that all connexin functions are related to communication channels and connexin functions may not be restricted to embryonic stages where intercellular communication has already been established. With this hypothesis in mind we searched for the expression of a $\mathrm{Cx} 43$ homologue in the African clawed frog Xenopus laevis, this connexin being the first and more ubiquitous expressed connexin found during mouse development (Davies et al., 1996). We also used sense and antisense RNA microinjection to investigate the role of Cx43 during the early development of $X$. laevis.

\section{Material and Methods}

\section{Biological material and embryo experiments}

Specimens of the African clawed frog Xenopus laevis (Daudin, 1802) (Amphibia, Anura, Pipidae) were maintained in aquaria at $16^{\circ} \mathrm{C}$ on a diet of purina dog chow. Egg induction and fertilization is described below.

Embryos were obtained from adult ( 2 years old) female $X$. laevis by hormone induced egg laying and fertilized in vitro using standard methods (Heasman et al., 1991) and staged according to Nieuwkoop and Faber (1967).

To assay for possible functions of the $\mathrm{Cx} 43$-like product in the early development of the nervous system we injected synthetic Cx43 antisense RNA (500 pg/10 nL) into embryos at the one or two-cell embryo stage. As a specific control for the antisense injection assays, embryos were injected with $1 \mathrm{ng}$ of $\mathrm{Cx} 38$ antisense RNA or $1 \mathrm{ng}$ of $\mathrm{Cx} 32$ antisense RNA. Also, other groups of 1 cell stage embryos were injected with mRNA in the vegetal region to demonstrate the presence of ectopic CT-Cx43 after injection.

\section{Molecular biology}

For in vitro RNA synthesis the $C x 43$ (subcloned in the PGEM $7 \mathrm{z}+$ vector), $C T-C x 43$ (subcloned in the PcDNA3 vector), chordin, goosecoid, engrailed-2, Xnot and $X b r a$ genes were transcribed as described by Harland and Weintraub (1985). The RNA (mRNA or antisense probe) was extracted by a standard procedure, precipitated with lithium chloride $7.5 \mathrm{M}$ and diluted in water treated with diethylpyrocarbonate (DEPC) for injection or in situ hybridization.

For the in situ hybridization of whole-mount embryos digoxigenin or fluorescein labeled $\mathrm{Cx} 43$, chordin, goosecoid, Xnot, and Xbra cDNAs antisense RNA probes were constructed (Harland and Weintraub, 1985) and embryos prepared, hybridized and stained by the method of Harland (Harland, 1991).

For the reverse transcriptase polymerase chain reaction (RT-PCR) the RNA was isolated from oocytes $(\mathrm{n}=10)$ 
and 1-cell stage Xenopus embryos $(\mathrm{n}=10)$ with TRizol (Gibco) and treated with Dnase I Rnase-free (Ambion) and used to synthesize cDNA. The RT-PCR was performed in a finale volume of $50 \mu \mathrm{L}$ at $94^{\circ} \mathrm{C}$ for $30 \mathrm{~s}, 58^{\circ} \mathrm{C}$ for $1 \mathrm{~min}$, $72{ }^{\circ} \mathrm{C}$ for $1 \mathrm{~min} 30 \mathrm{~s}$ and repeated for 33 cycles and the products were resolved in $1 \%(\mathrm{w} / \mathrm{v})$ agarose gel and stained with ethidium bromide. The RT-PCR was amplified using a set of specific primers for Xenopus $\mathrm{Cx} 43(\alpha 1)$ (forward 5 '-ggaattcggtacatgtatgggtttagc, reverse 5 '-ggggtaccaggtcg tggtctgctactag), xCx38 (forward 5'-gtggacagacgagcagtc ag, reverse 5'-actcaactttatgtttgcat), rat $\mathrm{Cx} 26$ (forward 5 '-atgtacaatggcttcttcat, reverse 5'-gggacttcaaatggcggcat.) and mouse Cx50 (forward 5'-aaaggaccgtgaagctgagg, reverse 5 '-acttctctcccacttccggt).

\section{Immunocytochemistry and Western blotting}

The embryos were fixed in $4 \%(\mathrm{w} / \mathrm{v})$ formaldehyde solution for $1 \mathrm{~h}$ and a polyclonal antibody for residues 346-360 of rat $\mathrm{Cx} 43$ ( $\mathrm{rCx} 43$ ) or a polyclonal antibody for $\beta$-catenin were added together with a secondary alkaline phosphatase-coupled anti-rabbit antibody and developed using Nitro-Blue Tetrazolium Chloride (NBT) and 5-Bromo-4-Chloro-3'-Indolyphosphate p-Toluidine Salt (BCIP) (Sigma).

To investigate the presence of connexins during the early development of Xenopus, protein extracts were prepared by direct lysis in SDS sample buffer from 2-cell stage control embryos $(n=10)$, embryos at the 2-cell stage treated with $\mathrm{Cx} 43$ antisense RNA $(\mathrm{n}=10)$ and embryos injected with antisense RNA and rescued with CT-Cx43 mRNA $(n=10)$. Rat liver and heart were used as a positive control. All protein extracts were analyzed by Western blotting.

The specific distribution of $\mathrm{Cx} 43$ expression in oocytes was determined by dissecting oocytes $(n=10)$ into the pigmented animal (An) and vegetal (Veg) hemisphere which were independently analyzed by Western blotting.

For Western blotting proteins were separated using $12.5 \%$ SDS-PAGE and transferred to Hybond-C extra (Amersham) membranes. Membranes were blocked using $5 \%$ non-fat dry milk in phosphate buffered saline Tween20 (PBST) and incubated for $1 \mathrm{~h}$ with the polyclonal antibody anti-rCx43 (Zymed), a polyclonal anti-rCx32 antibody or a monoclonal anti-actin antibody (Sigma) as probes and $1 \mathrm{~h}$ with the appropriate alkaline-phosphatasecoupled secondary antibody (Sigma) and developed with a standard protocol provided by the manufacturer.

Note that some specific methodological details are given in the legends to the accompanying figures.

\section{Results}

\section{Expression pattern of Cx43-like protein}

To investigate the presence of connexins during the early development of Xenopus, we first screened protein extracts from oocytes and 1-cell stage embryos using Western blotting. We detected a $40 \mathrm{KDa} \mathrm{Cx} 43$-like protein the oocytes and 1-cell stage embryos (Figure 1a, upper panel). The expression of this $\mathrm{Cx} 43$-like mRNA was detected by RT-PCR in the 1 cell stage embryos (Figure 1b).

The specific distribution of $\mathrm{Cx} 43$-like expression in the pigmented animal hemisphere and the vegetal hemisphere of dissected oocytes as detected by Western blotting is shown in Figure 1a. Surprisingly, we detected differential expression of a $\mathrm{Cx} 43$-like protein was in the animal and vegetal regions of the oocytes (Figure 1a, middle panel), the $\mathrm{Cx} 43$-like protein being more abundant in the animal hemisphere. In this experiment much more vegetal hemisphere protein was loaded on the gel (Figure 1a, lower panel, actin control). These analyses were done with Western blots, because Xenopus embryos are opaque and only a very thin surface of the embryos can be stained with antibodies and also because whole-mount staining is not quantitative. However, the specific distribution of this Cx43-like molecule in Xenopus oocytes and embryos was also confirmed by whole mount in situ hybridization and immunocytochemistry, the weakly-staining brown streaks visible in Figure 1 being the residual animal pole cortex pigments which we conserved in order to selectively identify the animal hemisphere and the dorsal regions of the embryos. The earliest detectable expression of $\mathrm{Cx} 43$-like mRNA (Figure 1c-e) and protein (Figure 1f-g) in oocytes occurred before fecundation only in the animal hemisphere, confirming our Western blot results. This expression pattern was maintained throughout the 1-cell stage embryo (Figure 1h, i). At this stage the competition assay with the rCx43 antigenic peptide blocked recognition by the polyclonal antibody used (Figure 1j). Subsequently, with the first division of the embryo, the Cx43-like message and protein appeared localized in the animal hemisphere (Figure $1 \mathrm{k}, \mathrm{l}$ ) but at the later 8 to 64 -cell stages mRNA and protein expression were confined to one domain of the animal blastomeres (Figure 1m, n, o), principally in less pigmented blastomeres in the presumptive dorsal region of the very early Xenopus embryos (Nieuwkoop and Faber, 1967), and was conserved in a specific dorsal pattern until the gastrula (Figure 1p, q) and neurula stage embryo (Figure 1r, s). These results are in line with the polarity found in 32-cell stage gap junctional permeability (Guthrie, 1984). Taken together these results suggest that a $\mathrm{Cx} 43$-like protein constitutes one of the first dorsal region markers appearing in early Xenopus embryos.

\section{Phenotypic effects of CT-Cx43 sense and antisense RNA}

The results of injecting antisense RNA into the animal hemisphere of Xenopus embryos to assay for possible functions of the Cx43-like product in the early development of the nervous system are shown in Figure 2a. In embryos injected with $\mathrm{Cx} 43$ antisense RNA at the 1-cell stage 

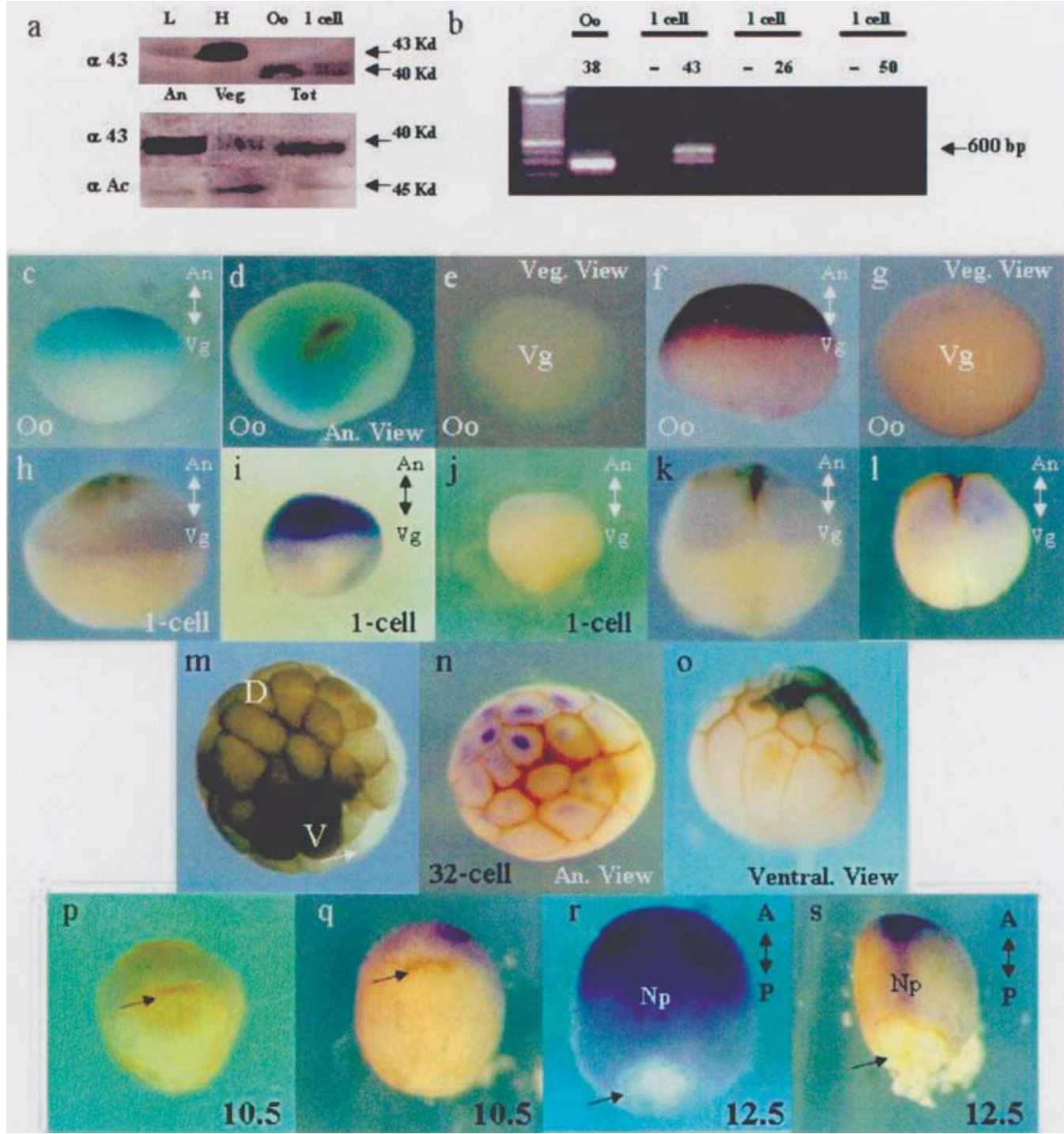

Figure 1 - A Cx43-like molecule is asymmetrically distributed during early developmental stages in Xenopus. Western blot (a), RT-PCR (b), whole-mount in situ hybridization (c, d, e, h, k, p and r) and immunocytochemistry (f, g, i, j, 1, n, o, q and s) of the Cx43-like molecule at different developmental stages. (a, upper panel) Oocytes (Oo) and 1-cell stage embryos (1-cell) extracts were immunoblotted using a polyclonal antibody anti-ratCx 43 , rat liver (L) and heart (H) were positive controls. The positions of the 43 and $40 \mathrm{KDa}$ molecular weight standards are also shown. (b) The size of the Cx43-like product was $\sim 600$ bp by RT-PCR, with the Cx38 as a positive control in the oocytes ( $\sim 385 \mathrm{bp})$. (j) Cx43-like antibody recognition was carried out using $100 \mu \mathrm{M}$ of the antigenic peptide. (p and q) At the 10-cell gastrula stage, mRNA and protein were localized in the dorsal region (vegetal view, arrowheads show the dorsal lip). ( $\mathrm{r}$ and s) At the 12.5-cell neurula stage the message and protein were distributed in a specific anterior dorsal pattern in the neural plate (dorsal view; arrowheads show the dorsal lip; $\mathrm{Np}=$ neural plate).

the expression of the Cx43-like protein was specifically reduced at the injection site (Figure 2, compare $\mathrm{c}$ with d) and was dramatically reduced in the whole animal region in the 2-4 cell stage (Figure 2, compare e with i) and partially reduced in the 32-cell stage embryos (Figure 2, compare $f$ with $\mathrm{j}$ ) as assayed by immunocytochemistry using a polyclonal antibody for rat $\mathrm{Cx} 43$. Similar results were obtained by Western blot analysis, demonstrating a total reduction of Cx43-like expression using the $\mathrm{Cx} 43$ antisense RNA approach (Figure 2b, compare columns $\mathrm{C}$ and $\mathrm{A}$ ). These experiments were done as a control to demonstrate that $\mathrm{Cx} 43$ antisense RNA could eliminate the Cx43 expression detected by our antibodies. We recovered expression of the
Cx43-like protein by injecting CT-Cx43 mRNA 15 min after injection of $\mathrm{Cx} 43$ antisense RNA, recovery being detected by western blotting (Figure 2a, upper panel, compare column $\mathrm{C}$ and $\mathrm{R}$ ) and immunocytochemistry (Figure $2 \mathrm{~m}$, n). The injection of mRNA into the embryos led to total recovery of phenotype shown in Figure 2p and the Cx32-like protein was not detected in protein extracts from these doubly-injected embryos (Figure 2b, lower panel). Actin expression was used as a control in the doubly-injected embryos and was slightly overexpressed, possibly due to the specific rearrangement of the cytoskeleton as a consequence of the treatment (Figure 2, compare $2 \mathrm{k}$, o and g). 

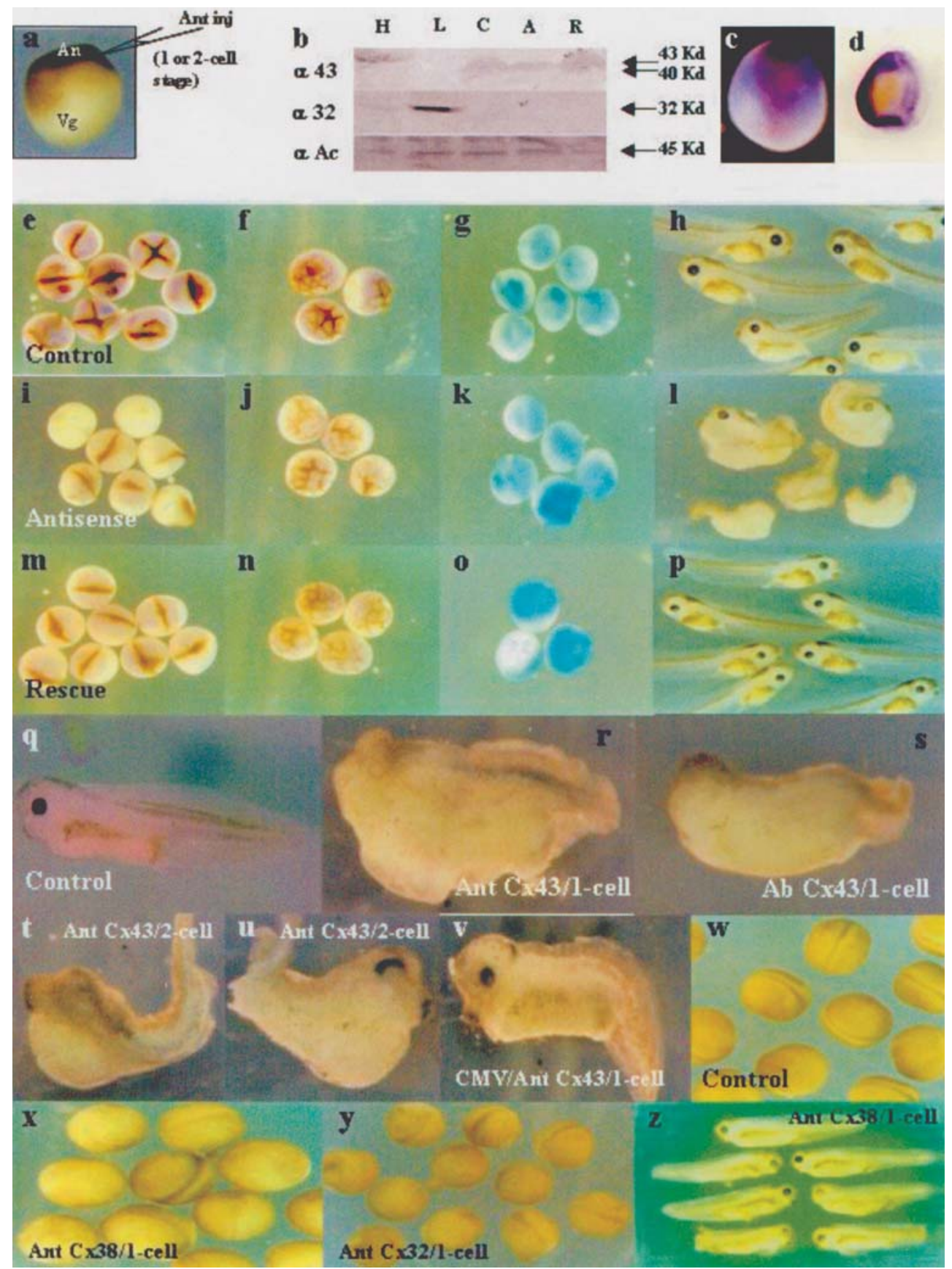

Figure 2 - Cx43 antisense RNA reduced Cx43 protein expression and induced a ventral phenotype in Xenopus embryos. Embryos were fixed at the 1, 2, 4, 32 cell stage and at stage 15 and 37/38. Western blot for Cx43 ( $\alpha 43)$, Cx32 ( $\alpha 32)$ and actin $(\alpha \mathrm{Ac})$ (a) and immunocytochemistry for Cx43 (c, d, e, f, i, j, m and n) and actin ( $\mathrm{g}, \mathrm{k}$ and $\mathrm{o}$ ) are shown. Control embryos, injected with milliQ water, showing normal expression of $\mathrm{Cx} 43$ (c, e and f) and actin ( $\mathrm{g}$ ) and the normal phenotype of the neurula (w) and tadpole stages (h and q). Embryos were injected at the 1-cell stage in the animal hemisphere with $0.5 \mathrm{ng}(\mathrm{d}$ and r) or $1 \mathrm{ng}(\mathrm{i}, \mathrm{j}, \mathrm{k}$ and $\mathrm{l}$ ) of Cx43 antisense RNA. Embryos were injected at the 1-cell stage in the animal hemisphere with $1 \mathrm{ng}$ of $\mathrm{Cx} 43$ antisense RNA and 15 min after with $1 \mathrm{ng}$ of Cx43 mRNA (m, n, o and p). Embryos were injected at the 1-cell stage with $0.25 \mathrm{ng}$ of a plasmid containing Cx43 antisense RNA under the control of the CMV promotor (v). Embryos were injected at the 1-cell stage in the animal hemisphere with $1 \mathrm{ng}$ of Cx32 (y) or Cx38 (x and z) antisense RNA. Embryos were injected at the 1-cell stage in the animal hemisphere with a polyclonal antibody against $\mathrm{rCx} 43$ (s). Embryos were injected at the 2-cell stage in the animal hemisphere with $0.5 \mathrm{ng}$ of $\mathrm{Cx} 43$ antisense RNA ( $\mathrm{t}$ and $\mathrm{u}$ ). (b) The protein extracts were prepared from 2-cell stage control embryos (C), 2-cell stage embryos treated with Cx43 antisense RNA (A) and embryos injected with antisense RNA and rescued with the CT-Cx43 mRNA (R), rat liver (L) and heart (H) were positive controls. The positions of the 43, 42, 40 and $32 \mathrm{KDa}$ molecular weight standards are shown. (d) The antisense RNA injected into 1-cell stage embryos reduced Cx43 protein expression exactly around the injected site. (h) A group of embryos showing the normal phenotype without injection of antisense or CT-Cx43 mRNA. (1) A group of embryos showing the dramatic effects of antisense RNA injection. (p) Embryos injected with antisense RNA were rescued by an additional injection of rat CT-Cx43 mRNA. (w) Control embryos in the neurula stage (stage 15). (x) Cx38 antisense RNA and (y) Cx32 antisense RNA did not induce any modification of the dorso-ventral phenotype at the neurula stage, with normal neurulation being present in $95 \%$ of Cx38 antisense injected embryos $(n=100)$ and $90 \%$ of Cx32 antisense injected embryos $(\mathrm{n}=100)$. ( $\mathrm{z})$ Embryos injected with Cx38 antisense RNA, showing no alteration of the dorso-ventral axis $(93 \%$ of injected embryos, $\mathrm{n}=161$ ) at the tadpole stage (compare $\mathrm{z}$ and $\mathrm{q}$ ). Notice that some embryos present a truncated tail and protuberances in the ventral region $(7 \%$ of injected embryos, $\mathrm{n}=161$ ). ( $\left.\mathrm{z}^{\prime}\right)$ Embryos injected with Cx32 antisense RNA, showing no alteration of the dorso-ventral axis. 
The phenotypic analysis of embryos injected with Cx43 antisense RNA into the animal region, showed the absence of eyes, a deformed head shape and severe ventralization (Figure 2, compare $\mathrm{h}$ with 1 and $\mathrm{q}$ with $\mathrm{r}$ ), this phenotype being present in $62 \%(n=50)$ of embryos injected with Cx43 antisense RNA. The same phenotype was also observed after injection of anti-rCx43 polyclonal antibody (Figure $2 \mathrm{~s}$ ), with $55 \%(\mathrm{n}=20)$ of embryos injected with anti-rCx43 polyclonal antibody displaying this phenotype. This ventralization was rescued by injection of $\mathrm{Cx} 43$ mRNA after the antisense RNA injection (Figure $2 p$ ). When one blastomere was injected in a 2-cell stage embryo, the injected side showed ventralization (Figure 2t) while the other side of the same embryo appeared almost normal (Figure $2 \mathrm{u}$ ), with $42 \%(\mathrm{n}=19)$ of injected embryos displaying this phenotype. However, injection of a plasmid carrying Cx43 antisense RNA under the control of the CMV promoter showed little effect on the embryos, which were absolutely normal with respect to the absence of eyes, head, cement gland and ventralization (Figure $2 \mathrm{v}$ ), indicating that the $\mathrm{Cx} 43$ connexin participates in dorso-ventral axis formation at a very early stage during development. As a specific control for antisense injection assays, Xenopus embryos were injected with $1 \mathrm{ng}$ of $\mathrm{Cx} 38$ antisense RNA (Figure 2x, $\mathrm{z}$ ), a maternal connexin, or $1 \mathrm{ng}$ of $\mathrm{Cx} 32$ antisense RNA (Figure 1y, z'), which were unable to produce dorso-ventral axis modifications in the neurula (Figure 2, Compare $x$ and $\mathrm{y}$ with w) and tadpole stage (Figure 2, compare z and z' with q).

The role $\mathrm{Cx} 43$ has in dorsal-ventral axis establishment was further investigated by injecting CT-Cx43 sense mRNA into the vegetal hemisphere of 2-cell stage embryos (Figure $3 \mathrm{a}$ ). We detected an expansion of the anterior neural plate in the injected side in stages 12.5 (Figure 3f) and 13.5 (Figure $3 \mathrm{~g}$ ) and at the $38 / 39$ stage the embryos showed an additional eye on the injected side (Figure 3, compare $h$ with i). This effect was observed in only $13 \%$ of sense injected embryos $(n=40)$. Also, other groups of 1 cell stage embryos were injected with mRNA in the vegetal region to demonstrate the presence of CT-Cx43 located ectopically after the injection of the mRNA (Figure 3, compare c-e with b).

\section{Molecular effects of antisense and sense CT-Cx43}

To define the molecular effects of $\mathrm{Cx} 43$-like ablation, we analyzed the expression of different dorsal markers, including $\beta$-catenin, in embryos injected with antisense Cx43 mRNA during the 1-cell stage. A strong reduction of both chordin (Figure 4, compare a with b) and xnot (Figure 4, compare $\mathrm{j}$ with $\mathrm{k}$ ) expression was observed in early gastrula (stage 12.5) and neurula embryos (stage 10.5), respectively. The expression of goosecoid was increased in 10 stage embryos or unaltered in stage 12.5 embryos (Figure 4, compare e with $\mathrm{f}$ and $\mathrm{g}$ with $\mathrm{h}$ ). Since goosecoid displays cell-autonomous activation, this suggest that cell-autonomous events also may play a role in the definition of the dorso-ventral axis in Xenopus (Lemaire and Gurdon, 1994). In addition, xbra showed increased expression with expanded domains into the animal region at the early gastrula stage (10.5 stage) (Figure 4, compare m with $n$ ). The expansion of the mesodermal plate could be responsible for the restriction of neural territories in the presumptive ectoderm and consequently in the loss of dorso-anterior structures. This phenomenon probably reflects the fact that the early patterning of the vertebrate mesoderm occurs by first establishing broad domains of gene expression which are subsequently refined by intergenic interaction (Ghysen and Dambly-Chaudière, 1988; Stern, 1954). Consistent with these results we de-

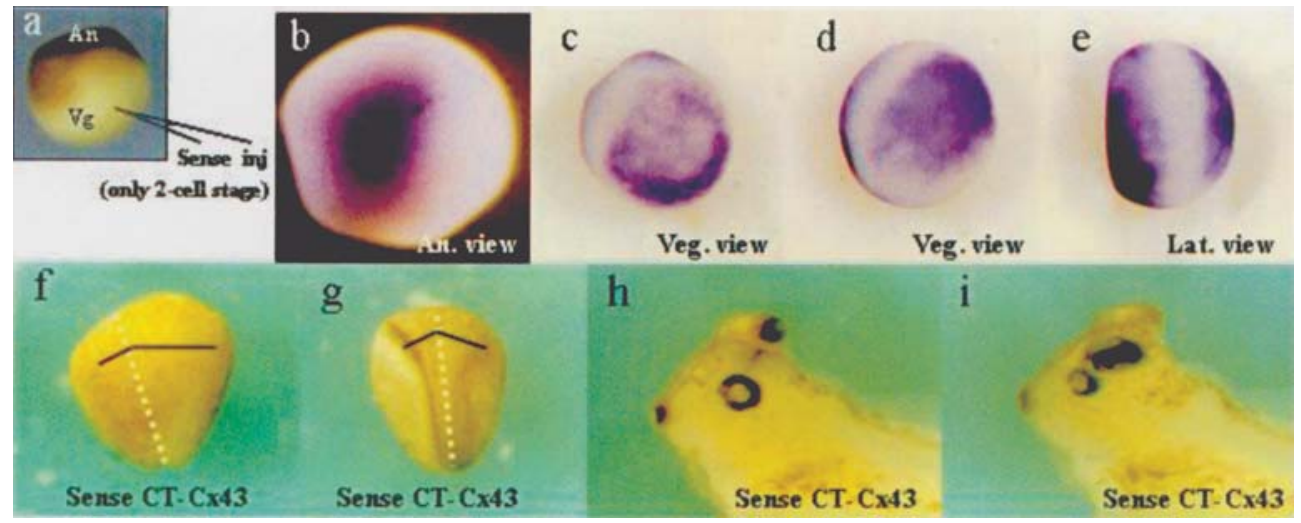

Figure 3 - Overexpression of CT-Cx43 mRNA induced a dorsal phenotype. Embryos were fixed at the 1-cell stage and at the 12.5/13.5 and 37/38 stage. Immunocytochemistry for Cx43 are shown in b, c, d and e. Embryos were injected at the 1-cell stage in the vegetal hemisphere with rat CT-Cx43 (c, d and e). Embryos were injected at the 2-cell stage in the vegetal hemisphere with $0.5 \mathrm{ng}$ of $\mathrm{rCx} 43 \mathrm{mRNA}$ (f, g, h and i). (a) Diagram showing the injection site of CT-Cx43 mRNA at 1 or 2-cell stage embryos. (b) Control embryo showing normal expression of Cx43. (c, d and e) Embryos showing the ectopic expression of CT-CX43, demonstrating overexpression before the first cellular division. The overexpression of the CT-Cx43 message produced phenotypic alteration of the dorso-ventral axis. At the 12.5-stage (f) and 13.5-stage (g) the anterior neural plate was expanded, suggesting morphological enlargement of the neural tissue on the injected side. The size of each side of the neural plate is indicated by black lines. At stage 38 the uninjected side presented a normal phenotype (h) but the injected side showed an ectopic eye (i, arrowhead). 
tected a strong reduction in $\beta$-catenin expression in the 1-cell stage embryos injected with $\mathrm{Cx} 43$ antisense mRNA during the same stage (Figure 4).

To investigate the molecular effects of CT-Cx43 overexpression, we analyzed the expression of chordin, goosecoid, xnot, engrailed-2 and $\beta$-catenin in 1-cell stage embryos which had had their vegetal region injected with CT-Cx43 sense mRNA. We detected expanded chordin and goosecoid expression at the posterior neural plate of 12.5 stage embryos (Figure 4c, i). When one blastomere of a 2-cell stage embryo was injected with the Cx43 antisense mRNA chordin expression was reduced only in the injected side (Figure 4d). The expression of xnot was increased with expanded domains of the lateral lines before gastrulation in a 10.5 stage embryo. We also detected ectopic expression of engrailed-2 (En-2) in the ventral region of tadpole stage embryos (Figure 4p-q, this phenotype being present in $57 \%$ of injected embryos, $n=69$ ) when compared with normal En-2 expression (Figure 4o, s), this being a sign of embryo dorsalization. Some embryos displayed complete inversion of engrailed-2 expression without dorsal expression and showing a

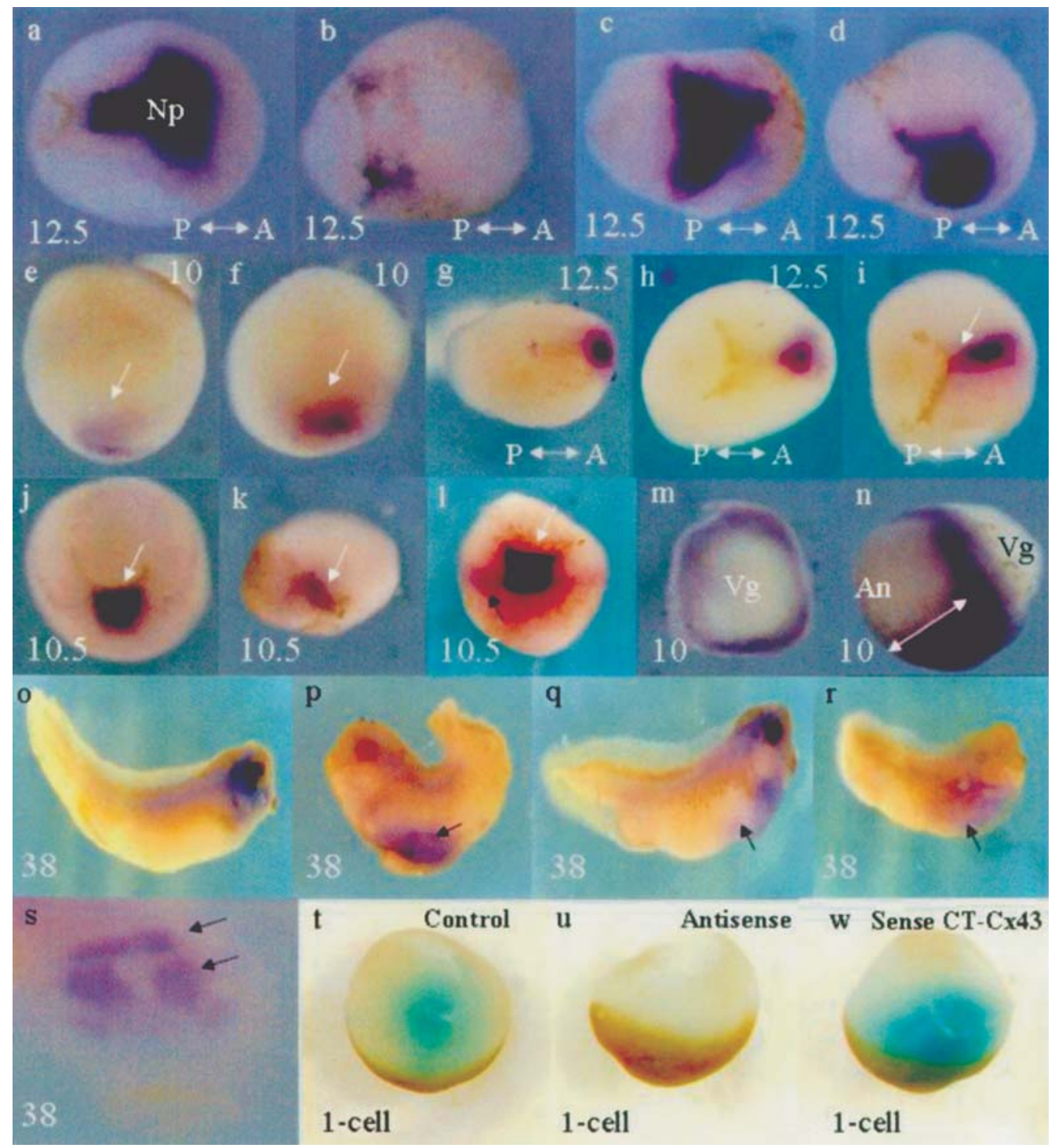

Figure 4 - Cx43 antisense mRNA disrupted the expression of dorsal markers $x$ not, chordin and $\beta$-catenin, and Cx43 sense mRNA produced ectopic expression of chordin, goosecoid, xnot, engrailed-2 and $\beta$-catenin. Embryos were fixed at the 1-cell stage ( $\mathrm{t}, \mathrm{u}$ and $\mathrm{v}), 10(\mathrm{e}, \mathrm{f}, \mathrm{m}$ and $\mathrm{n}), 10.5(\mathrm{j}, \mathrm{k}$ and $\mathrm{l}) 12.5$ (a, b, c, d, g, h and i) and 38/39 (o, p, q, r and s) stages. Control embryos were injected with milliQ water treated with DEPC (a, e, g, j, m o and s), the antisense embryos were injected at the 1-cell (b, f, h, $\mathrm{k}, \mathrm{n}$ and $\mathrm{t}$ ) or 2-cell stage (d) with $0.5 \mathrm{ng}$ of the Cx43 antisense RNA and sense embryos were injected at the 1-cell stage with $0.5 \mathrm{ng}$ of the Cx43 mRNA (c, i, l, p, q, r and u). Specifically the embryos showed in $\mathrm{t}, \mathrm{u}$ and v were injected at the 1 cell stage and captured $45 \mathrm{~min}$ after injection. (a-d) chordin expression. (e-i) goosecoid expression. (j-1) xnot expression. ( $\mathrm{m}$ and $\mathrm{n}$ ) Xbra expression. (o-s) En-2 expression. (t-v) $\beta$-catenin expression. (a) $\mathrm{Np}=$ neural plate. (e and f) The white arrow indicates goosecoid expression. (i) The white arrow indicates the anterior expression of goosecoid in the medial region of the embryo. ( $\mathrm{j}$ and $\mathrm{k}$ ) white arrow indicate the dorsal lip. (1) The xnot expression was increased and the lateral lines clearly expanded (black arrow). (p-r) The black arrow indicates ectopic expression of En-2 in the ventral region. (s) Control embryo showing the normal expression of engrailed-2 in the mid-hind brain (black arrow). 
complete neuralization of the ventral region (Figure 4r, this phenotype being present in $10 \%$ of injected embryos, $\mathrm{n}=69$ ). These results are consistent with the assumption that that the function of the Cx43-like protein is to dorsalize embryos and suggests that neural plate expansion could be caused by alterations in the expression of dorsal genes before or during neurulation, reinforcing the importance of connexins in the establishment and definition of neural territories in the early development of $X$. laevis. Coherently, the overexpression of CT-Cx 43 produced a clear increment of $\beta$-catenin concentration in the Nieuwkoop center (Figure 4, compare v with t). Our analyses of $\beta$-catenin expression in embryos injected with sense or antisense CT-Cx 43 mRNA showed that CT-Cx 43 modified the earliest molecular marker which acts by initiating the cascade of events that induces the establishment of the dorso-ventral axis. The observed effect on $\beta$-catenin expression is also coherent with the observed phenotypic effect in embryos treated with CT-Cx43 mRNA. However it is not clear how the asymmetric distribution of connexins relates to the establishment of differences in the dorso-ventral axis.

\section{Discussion}

\section{Heterologous characterization of $\mathrm{Cx} 43$-like protein}

Connexin proteins have a well-established role in cell-cell communication (Kumar and Gilula, 1996). Along with the expansion of the list of connexin-associating proteins, reports have appeared that suggest that in addition to their channel function connexins might have other roles such as transcriptional and cytoskeletal regulation and that these functions are dependent of the specific interaction of CT-Cx43 and cellular proteins (Giepmans, 2004). The Xenopus Cx43 has been cloned by Gimlich et al. (1990), with this clone presented $87 \%$ of amino acids identities and $89 \%$ of nucleotides identities between Rat and Xenopus $\mathrm{Cx} 43$. Several works have been published using rat $\mathrm{Cx} 43$ as a tool to study the role of the gap junction in the early development of Xenopus. For example, (Paul et al., 1995) used a dominant negative approach with rat $\mathrm{Cx} 43$ mutated to block the activity of cell-cell communication in embryos, while (Levin and Mercola, 1998) described the importance of connexin in the establishment of left-right asymmetry using rat $\mathrm{Cx} 43$ as a tool. We applied the method of Levin and Mercola to detect a $\mathrm{Cx} 43$ homologue in the very early development of Xenopus and used antisense or ectopic sense mRNA injection assays and phenotypic or molecular analysis of the resulting embryos to propose a role for $\mathrm{Cx} 43$ in the induction of the dorso-ventral axis. The high identity between Rat and Xenopus Cx43 makes our antisense RNA an appropriate probe for detection and injection in Xenopus embryos. Moreover the primers used for our RT-PCR experiments were generic primers that we made taking full advantage of the similarity between $\mathrm{Cx} 43$ in different species.

The present 'connexin system' nomenclature for gap junction subunits is primarily based on the molecular weight of proteins deduced from cDNA sequences (Beyer et al., 1987), but, however, very closely related proteins from different species can have different predicted molecular weights. For instance, the mammalian $\mathrm{Cx} 32$ is $32 \mathrm{kD}$ whereas the Xenopus homologue is $30 \mathrm{kD}$ (Gimlich et al., 1988). Although he $\mathrm{Cx} 43$ protein is highly homologous between Rat and Xenopus (Gimlich et al., 1990) Xenopus $\mathrm{Cx} 43$ can be found in several isoforms depending on the tissue analyzed. For example Gimlich et al., (1990) detected several variable-sized $\mathrm{Cx} 43$ transcripts from the ovary and characterized another $\mathrm{Cx} 43$ from Xenopus heart that was very abundant but smaller than the first cloned Xenopus $\mathrm{Cx} 43$. These observations are supported by our findings outlined in the present paper where we describe the detection of a $40 \mathrm{kD} \mathrm{Cx} 43$-like protein in the very early development of Xenopus.

\section{Specificity of the probes and experiments}

We consider that in order to demonstrate the specificity of any antisense RNA effect four criteria must be fulfilled. One criterion is to establish that other related and unrelated antisense RNAs have no such effects at comparable or higher doses. The $\mathrm{Cx} 38$ connexin is a unique maternal connexin representative of the $\alpha$-connexin family (as is $\mathrm{C} \times 43$ ) while $\mathrm{C} \times 32$ is the principal representative of the $\beta$-connexin family, both these connexins being used by us in doses twice as large as that used for $\mathrm{Cx} 43$ but did not produced any phenotypic effect in the embryos (Figures 2x-z). A second criterion is to establish, by Western blot analysis and other techniques, that the antisense RNA is specifically decreasing the steady-state level of the protein under study while having no effect on other proteins used as controls. In our study we found reduced expression of a Xenopus $\mathrm{Cx} 43$-like protein by western blotting (Figure $2 \mathrm{~b}$ ) and immunocytochemistry (Figure 2d, i) while the expression of the actin positive control remained unaltered. A third criterion is to show that the phenotypic effects of appropriate antisense mRNA can be rescued by co-expression of wild type mRNA, as illustrated in Figure 2p. A fourth criterion is to demonstrate that antisense mRNA effects on connexin expression can be rescued by co-expression of wild type mRNA. All these criteria were fulfilled in our experiments, which thus demonstrate the specificity of the effect of appropriate antisense RNA against $\mathrm{Cx} 43$.

\section{The antisense approach}

Controversy surrounding the use of antisense techniques, especially in Xenopus embryos are common in the literature, with some groups having been unable to reproduce antisense work published by other groups. The rapid degradation of the antisense oligonucleotides used in these 
studies has been suggested as a cause for the variability of reported results, and Morpholine oligo complementary Heasman techniques aimed at stabilizing the injected RNA have been proposed (Heasman, 2002; Heasman et al., 2000). In that regard we would like to point out that we did not use Morpholines and we presume that our antisense has at least 300-400 base pairs, rendering it more prone to rapid degradation. Secondly, and possibly more importantly, we have shown that the antisense injections decreased the expression of the target protein, at least transiently $(2 \mathrm{~b}, \mathrm{~d}, \mathrm{i}, \mathrm{j})$. We appear to have found the correct time window for decreasing expression of the $\mathrm{Cx}$-like molecule, this being one of the major findings of our study. We believe that we were dealing with this $\mathrm{Cx}$-like molecule at a stage when it was not acting as an intercellular channel and the transient decrease of its expression during this critical time period during development produced the effects described in this paper (Figure 21, r). In that regard, we feel that the main criticism directed at the use of antisense strategies (Heasman, 2002) does not affect our work. In fact, we think that if the expression of the protein is decreased for longer periods the effects reported in the literature for connexins will manifest themselves, i.e. delamination of cells in gastrulation and a high percent of non-viable embryos (Paul et al., 1995). In our opinion, the host-transfer technique is unsuitable for achieving selective reduction in the 1 to 2 cell stage. We have also shown that antibody injection produces the same effect as antisense techniques (Figure 2s), sense RNA producing exactly the opposite effects to the antisense treatment (Figure 3). Our data also shows that antisense injections work, at least during the developmental period when it appears that that the target molecule plays a fundamental role in establishing the dorso-ventral patterning of the embryo.

\section{Connexins and their interactions}

The binding of $\alpha-\beta$-catenins to the zonula occludens-1 (ZO-1) protein is required for $\mathrm{Cx} 43$ transport to the plasma membrane during the assembly of gap junctions (Wu et al., 2003) and the ZO-1 'scaffold' protein might recruit signaling proteins into $\mathrm{Cx} 43$-based gap junctions (Giepmans, 2004). Recent studies have shown the formation of an $\alpha$ - $\beta$-catenin- (ZO-1) -Cx43 complex in rat cardiomyocytes and epithelial cells. The first structural characterization of a connexin domain integrated into a multimolecular complex was recently published by (Sorgen et al., 2004). It is known that c-Src can disrupt the connexin43 (Cx43)-zonula occludens-1 (ZO-1) interaction and lead to down-regulation of gap junction intercellular communication, the ZO-1 and c-Src binding sites corresponding to widely separated $\mathrm{Cx} 43$ domains (Sorgen et al., 2004). The c-Src tyrosine kinase phosphorylates CT-Cx 43 and is involved in $\mathrm{G}$ protein-mediated inhibition of $\mathrm{Cx} 43$ gap junctional communication (Giepmans, 2004).
(Moyer and Ehrlich, 2003) have shown that in normal fibroblasts $\mathrm{Cx} 43$ and $\beta$-catenin were evenly distributed throughout the cell, but in cells treated with hyaluronan these proteins were co-localized to the cell surface. Furthermore, (Collares-Buzato et al., 2001) have shown that connexin 43 and $\beta$-catenin are co-localized in neonatal pancreatic islets cells treated in vitro with prolactin and considered this interaction to be an important event in the in vitro maturation process of neonatal pancreatic islets cells. (Ai et al., 2000) characterized the Wnt family of secreted polypeptides as regulators of $\mathrm{Cx} 43$ expression and gap junction channel function in mouse intact hearts and dissociated mouse myocytes and have shown that in response to Wnt signaling Cx43 co-localized with $\beta$-catenin in the junctional membrane and coherently in a transgenic cardiomyopathic mouse model exhibiting ventricular arrhythmias and gap junctional remodeling, $\beta$-catenin and $\mathrm{Cx} 43$ expression being downregulated in conjunction.

These studies by other workers support our experiments involving mRNA overexpression and the injection of antisense in which we observed the simultaneous increase or reduction of $\beta$ - catenin and $C x 43$ (Figure $4 t, u, v$ ). Despite lack of evidence of a direct interaction between connexins and $\beta$-catenin to date, the physical interactions found so far and a possible function in gap junctional channel-independent regulation of gene expression by $\mathrm{Cx} 43$ sequestering transcriptional regulators are noteworthy and relevant to developmental biology.

On the other hand, (Giepmans et al., 2001) identified the interaction between CT-Cx43 and alpha/beta-tubulin dimers (microtubules) which extend with their distal ends to $\mathrm{Cx} 43$-based gap junctions, suggesting that $\mathrm{Cx} 43$ gap junctions may play a novel role in regulating microtubule stability in contacted cells. Other observations support the premise that direct association of the cytoskeleton with gap junctions plays a significant role in the regulation of $\mathrm{Cx} 43$ expression and distribution through integrin-mediated signal transduction pathways (Guo et al., 2003). It may be that the channel-independent effects of connexins, which have now been reported by many groups, might be explained by dysfunction or function of connexin-tail interacting proteins (Goodenough and Paul, 2003).

\section{Overexpression approach}

It has been pointed out by Naus et al. (2000) that the overexpression of connexins produces upregulation of several genes and important changes in the cytoskeleton coherent with their specific interactions cited above. Some authors have raised criticisms with regard to these studies, which are considered weak, because upregulation apparently confuses functional interpretations (Goodenough and Paul, 2003), but the differential display strategies have been used precisely to identify a number of genes which are differentially expressed in specific conditions to under- 
stand the complex network of interactions and regulation in the cytoplasm of the cells. In C6 glioma cells transfected with $\mathrm{Cx} 43$ it has been possible to characterize several genes, including those coding for a number of secreted factors which may play a role in modulating the tumor phenotype of the cells, helping to better understand the functional studies carried out with these cells (Naus et al., 2000). However, on the other hand, there are no publications describing the effect of CT-Cx43 overexpression on the cellular genes that can affect the interpretations of our data.

\section{Final Considerations}

During the research described in this paper we detected both mRNA and protein at the 1 or 2-cell stage of development when cell-cell communication is not yet established. The connexin signal detected suggests a coherent pattern with a maternal determinant, mainly based on the asymmetrical distribution of the connexin protein in the animal-vegetal axis of oocytes and embryos. Our functional studies of blockade and overexpression of the CT-CX43 factor show that this can modify the establishment of the dorso-ventral axis, suggesting an important role for CTCx43 in the early formation of this axis. (Nascone and Mercola, 1997) have pointed our that dorso-ventral asymmetry is important in establishing the left-right patterning of the embryo and connexins are known to be involved in the genesis of this patterning (Levin and Mercola, 1998). The dorso-ventral axis is established during the initial events of embryonic development, before left-right axis formation. Since the critical events involved in dorsoventral axis formation occurs between fecundation and the first cleavage of the embryo, strategies to ablate $\mathrm{Cx}$ expression in 4-8 cell stage embryos cannot interfere with dorsoventral patterning because they affect only left-right axis formation.

The carboxy-terminal $(\mathrm{COOH})$ domains of connexins are located in the intracellular space and have important roles in regulation of cell-cell communication (Bruzzone et al., 1996). Changes in Cx43-mediated gap junctional communication by growth factors (Hossain et al., 1999), oncogenes (Kanemitsu et al., 1997; Loo et al., 1995) and activators of protein kinases (Kanemitsu et al., 1998; Kanemitsu et al., 1997; Kim et al., 1999; Warn-Cramer et al., 1996) have been shown to require an intact $\mathrm{COOH}$ domain. It is known that $\mathrm{Cx} 43$ is also a substrate for phosphorylation by protein kinase $\mathrm{C}$ (PKC), Mitogen-Activated Protein Kinase (MAPK) and Src protein kinase (v-Src), in which the $\mathrm{SH} 3$ (Src Homology-3) domain of v-Src binds to the $\mathrm{COOH}$ domain of Cx43 (Hossain et al., 1999). This opens the possibility that the carboxyl domain of $\mathrm{Cx} 43$, through association with $\mathrm{SH} 2$ (Src homology-2) and $\mathrm{SH}$-containing proteins, could direct these proteins to separate compartments within the cytoplasm. The posterior cleavage of the embryo would then help to establish and generate the dorso-ventral axis. Based on these results, we propose that a Cx43-like protein molecule acts as a maternal protein during the very early development in Xenopus and has a major role in the formation of the dorso-ventral axis.

\section{Acknowledgments}

We wish to thank Dr. A.C. Campos de Carvalho and M.O. Masuda for the opportunity to start this work as well for the critical review of this manuscript; Dr. E.L. Hertzberg for providing the anti-Cx43 antibodies; Dr. E. De Robertis for goosecoid and chordin; Dr. K. Cho for brachyury and Dr. D. Kimmelman for Xnot cDNA clones. We also thank Dr. E. Kalapotakis for the original design of Cx primers. We are grateful to D. Avanzi for technical assistance. This work was supported by grants from the Brazilian agency FAPERJ.

\section{References}

Ai Z, Fischer A, Spray DC, Brown AMC and Fishman GI (2000) Wnt-1 regulation of connexin43 in cardiac myocytes. J Clin Invest 105:161-171.

Beyer EC, Paul DL and Goodenough DA (1987) Connexin43: A protein from rat heart homologous to a gap junction protein from liver. J Cell Biol 105:2621-2629.

Bruzzone R, White TW and Goodenough DA (1996) The cellular internet: On-line with connexins. BioEssays 18:709-718.

Collares-Buzato CB, Leite AR and Boschero AC (2001) Modulation of gap and adherens junctional proteins in cultured neonatal pancreatic islets. Pancreas 23:177-185.

Davies TC, Barr KJ, Jones DH, Zhu D and Kidder GM (1996) Multiple members of the connexin gene family participate in preimplantation development of the mouse. Developmental Genetics 18:234-243.

Ghysen A and Dambly-Chaudière C (1988) From DNA to form: The achaete-scute complex. Genes and Development 2:495-501.

Giepmans BN, Verlaan I and Moolenaar WH (2001) Connexin-43 interactions with $\mathrm{ZO}-1$ and alpha- and beta-tubulin. Cell Commun Adhes 8:213-217.

Giepmans BNG (2004) Gap junctions and connexin-interacting proteins. Cardiovascular Research 62:233.

Gimlich RL, Kumar NM and Gilula NB (1988) Sequence and developmental expression of mRNA coding for a gap junction protein in Xenopus. J Cell Biol 107:1065-1073.

Gimlich RL, Kumar NM and Gilula NB (1990) Differential regulation of the levels of three gap junction mRNAs in Xenopus embryos. J Cell Biol 110:597-605.

Goodenough DA and Paul DL (2003) Beyond the gap: Functions of unpaired connexon channels. Nature Reviews Molecular Cell Biology 4:285-295.

Guger KA and Gumbiner BM (1995) [beta]-catenin has Wnt-like activity and mimics the nieuwkoop signaling center in Xenopus dorsal-ventral patterning. Developmental Biology 172:115-125.

Guo Y, Martinez-Williams C and Rannels DE (2003) Gap junction-microtubule associations in rat alveolar epithelial cells. Am J Physiol Lung Cell Mol Physiol 285:L1213-1221.

Guthrie SC (1984) Patterns of junctional communication in the early amphibian embryo. Nature 311:149-151. 
Harland R and Weintraub H (1985) Translation of mRNA injected into Xenopus oocytes is specifically inhibited by antisense RNA. J Cell Biol 101:1094-1099.

Harland RM (1991) In situ hybridization: An improved wholemount method for Xenopus embryos. Methods Cell Biol 36:685-695.

Heasman J (2002) Morpholino oligos: Making sense of antisense? Developmental Biology 243:209.

Heasman J, Holwill S and Wylie C (1991) Fertilization of cultured Xenopus oocytes and use in studies of maternally inherited molecules. Methods Cell Biol 36:45-60.

Heasman J, Kofron M and Wylie C (2000) [beta]-catenin signaling activity dissected in the early Xenopus embryo: A novel antisense approach. Developmental Biology 222:124.

Hossain MZ, Jagdale AB, Ao P, Kazlauskas A and Boynton AL (1999) Disruption of gap junctional communication by the platelet-derived growth factor is mediated via multiple signaling pathways. J Biol Chem 274:10489-10496.

Kageura H (1997) Activation of dorsal development by contact between the cortical dorsal determinant and the equatorial core cytoplasm in eggs of Xenopus laevis. Development 124:1543-1551.

Kanemitsu MY, Jiang W and Eckhart W (1998) Cdc2-mediated phosphorylation of the gap junction protein, connexin 43, during mitosis. Cell Growth Differ 9:13-21.

Kanemitsu MY, Loo LWM, Simon S, Lau AF and Eckhart W (1997) Tyrosine phosphorylation of connexin 43 by v-Src is mediated by SH2 and SH3 domain interactions. J Biol Chem 272:22824-22831.

Kim DY, Kam Y, Koo SK and Joe CO (1999) Gating connexin 43 channels reconstituted in lipid vesicles by mitogen-activated protein kinase phosphorylation. J Biol Chem 274:55815587.

Kumar NM and Gilula NB (1996) The gap junction communication channel. Cell 84:381-388.

Landesman Y, Postma FR, Goodenough DA and Paul DL (2003) Multiple connexins contribute to intercellular communication in the Xenopus embryo. J Cell Sci 116:29-38.

Larabell CA, Torres M, Rowning BA, Yost C, Miller JR, Wu M, Kimelman D and Moon RT (1997) Establishment of the dorso-ventral axis in Xenopus embryos is presaged by early asymmetries in beta-catenin that are modulated by the Wnt signaling pathway. J. Cell Biol 136:1123-1136.

Lemaire P and Gurdon JB (1994) A role for cytoplasmic determinants in mesoderm patterning: Cell-autonomous activation of the goosecoid and Xwnt- 8 genes along the dorsoventral axis of early Xenopus embryos. Development 120:11911199.

Levin M and Mercola M (1998) Gap junctions are involved in the early generation of left-right asymmetry. Developmental Biology 203:90-105.

Levin M and Mercola M (1999) Gap junction-mediated transfer of left-right patterning signals in the early chick blastoderm is upstream of Shh asymmetry in the node. Development 126:4703-4714.

Lo CW (1996) The role of gap junction membrane channels in development. Journal Bioenergetic and Biomembrane 28:337-383.

Lo CW (1999) Genes, gene knockouts, and mutations in the analysis of gap junctions. Developmental Genetics 24:1-4.

Loo LWM, Berestecky JM, Kanemitsu MY and Lau AF (1995) pp60 Src-mediated phosphorylation of connexin 43, a gap junction protein. J Biol Chem 270:12751-12761.
Moyer KE and Ehrlich HP (2003) Modulation of human fibroblast gap junction intercellular communication by hyaluronan. Journal of Cellular Physiology 196:165-170.

Nagajski DJ, Guthrie S, Ford CC and Warner AE (1989) The correlation between patterns of dye transfer through gap junctions and future developmental fate in Xenopus: The consequences of u.v. irradiation and lithium treatment. Development 105:747-755.

Nascone N and Mercola M (1997) Organizer induction determines left-right asymmetry in Xenopus. Developmental Biology 189:68-78.

Naus CCG, Bond SL, Bechberger JF and Rushlow W (2000) Identification of genes differentially expressed in C6 glioma cells transfected with connexin43. Brain Research Reviews 32:259.

Nieuwkoop P and Faber J (1967) Normal Table of Xenopus laevis (Daudin). North-Holland Publishing Company, Amsterdam.

Olbina G and Eckhart W (2003) Mutations in the second extracellular region of connexin 43 prevent localization to the plasma membrane, but do not affect its ability to suppress cell growth. Mol Cancer Res 1:690-700.

Olson DJ, Christian JL and Moon RT (1991) Effect of Wnt-1 and related proteins on gap junctional communication in Xenopus embryos. Science 252:1173-1176.

Paul DL, Yu K, Bruzzone R, Gimlich RL and Goodenough DA (1995) Expression of a dominant negative inhibitor of intercellular communication in the early Xenopus embryo causes delamination and extrusion of cells. Development 121:371381.

Segretain D, Decrouy X, Dompierre J, Escalier D, Rahman N, Fiorini C, Mograbi B, Siffroi J-P, Huhtaniemi I, Fenichel P and Pointis G (2003) Sequestration of connexin 43 in the early endosomes: An early event of Leydig cell tumor progression. Molecular Carcinogenesis 38:179-187.

Sokol SY, Klingensmith J, Perrimon N and Itoh K (1995) Dorsalizing and neuralizing properties of Xdsh, a maternally expressed Xenopus homolog of dishevelled. Development 121:1637-1647.

Sorgen PL, Duffy HS, Sahoo P, Coombs W, Delmar M and Spray DC (2004) Structural changes in the carboxyl terminus of the gap junction protein connexin 43 indicates signaling between binding domains for c-Src and Zonula occludens-1. J Biol Chem 279:54695-54701.

Stern C (1954) Two or three bristles. Am Sci 42:213-247.

Warn-Cramer BJ, Lampe PD, Kurata WE, Kanemitsu MY, Loo LWM, Eckhart W and Lau AF (1996) Characterization of the mitogen-activated protein kinase phosphorylation sites on the connexin-43 gap junction protein. J Biol Chem 271:3779-3786.

Warner AE, Guthrie SC and Gilula NB (1984) Antibodies to gap-junctional protein selectively disrupt junctional communication in the early amphibian embryo. Nature 311:127-131.

Wu JC, Tsai RY and Chung TH (2003) Role of catenins in the development of gap junctions in rat cardiomyocytes. Journal of Cellular Biochemistry 88:823-835.

Yuge M, Kobayakawa Y, Fujisue M and Yamana K (1990) A cytoplasmic determinant for dorsal axis formation in an early embryo of Xenopus laevis. Development 110:1051-1056.

Zhang Y-W, Kaneda M and Morita I (2003) The gap junctionindependent tumor-suppressing effect of connexin 43. J Biol Chem 278:44852-44856.

Associate Editor: Ricardo Guelerman P. Ramos 